\title{
Effects of pedagogical movie English subtitles on EFL learners' vocabulary improvement
}

\author{
Rostam Shirazi, Roya $\bowtie$ \\ English Department, Najafabad Branch, Islamic Azad University, Najafabad, Iran (r.shirazi90@yahoo.com) \\ Hesabi, Akbar \\ English Department, University of Isfahan, Isfahan, Iran (a.hesabi11@yahoo.com) \\ Simin, Shahla \\ English Department, Najafabad Branch, Islamic Azad University, Najafabad, Iran (shahlasimin@yahoo.com)
}

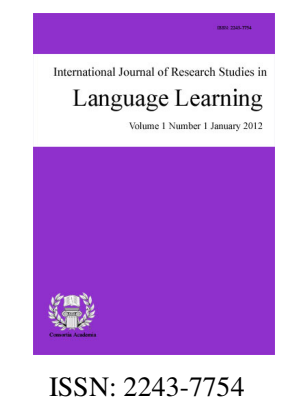

Online ISSN: 2243-7762

OPEN ACCESS

\section{Abstract}

Using movies might be one way of providing context for vocabulary learning. However, there is a growing debate on the best mode of subtitles in movies as a pedagogical aid in language learning. This study is an attempt to examine the possible effects of two kinds of pedagogical movie subtitles on intermediate-level EFL learners' English vocabulary improvement. To this end, 28 females, who were randomly selected from larger sample of 35 EFL learners from a language institute in Isfahan, took part in the study. The participants, aged 12 to 16, were then divided into two groups (controllable and uncontrollable subtitle groups) using Oxford Placement Test (OPT). The first group viewed an uncontrollable subtitled movie (English dialogues with unrepeated L2 subtitles) whereas the second one viewed a controllable subtitled movie (English dialogues with repeated L2 subtitles). Instructional materials included 10 parts of a movie, titled 'Tangled' (produced in 2010). The EFL participants were instructed on how to learn words in the movie in several sessions. To collect data, a content specific vocabulary test which consisted of 30 multiple-choice items, was developed by the present researchers and was administered as the pretest and posttest of the study. The results of analysis of covariance on the pretest and posttest vocabulary test scores showed that the participants in the controllable English subtitle group performed significantly better than the participants in the uncontrollable English subtitle group. By implication, curriculum developers and EFL instructors can utilize the findings of this study to include movies with target language subtitles to enhance EFL learners' vocabulary learning.

Keywords: pedagogical English movies; English subtitle; L2 vocabulary learning 


\section{Effects of pedagogical movie English subtitles on EFL learners' vocabulary improvement}

\section{Introduction}

Learning a foreign language is useful in various ways; it can help to better understand other cultures, access knowledge, and have a better chance of getting jobs; it also offers cognitive and metalinguistic advantages. Unfortunately, because of a great amount of vocabulary which the learners need to acquire in order to be fluent in a language, learning a foreign language is a difficult and long process. Nonetheless, teaching second/foreign (L2) through subtitled movies can assist foreign language learning (Bisson, 2013).

Vocabulary plays an essential role in L2 learning/acquisition and academic achievement, and the crucial role of vocabulary learning cannot be denied as there are numerous materials and sources in the market which promote the improvement of L2 learners' vocabulary knowledge (Zarei \& Gujjar, 2012). Vocabulary is also "at the heart of developing communicative language proficiency and building meaningful interactions" (Amiryousefi, 2015, p. 29). It is argued that English as a foreign language (EFL) learners need to achieve a threshold level of the target vocabulary to be able to communicate fluently in L2 i.e., English and understand an authentic text in L2 (Laufer \& Ravenhorst-Kalovski, 2010). Due to the reconceptualization of vocabulary learning, many L2 teachers have been recommended to assist the implicit and incidental vocabulary learning instead of explicit vocabulary teaching. Trying to provide instances for the incidental vocabulary learning has also been highlighted in recent reviews of vocabulary teaching (Hunt \& Beglar, 1998; Nagy, 1997).

According to the Krashen's acquisition theory, 'comprehensible input' is a major element in the acquisition of an L2 (Yang-dong \& Cai-fen, 2007). And multimedia can provide massive quantities of authentic and comprehensible input for L2 learners. Through the combination of audio and visual input, deeper comprehension is provided for the learners (Wang, 2012). As several researchers (e.g., Brett, 1995; Egbert \& Jessup, 1996; Khalid, 2001) have pointed out, multimedia have beneficial effects on language learning because of authentic and rich comprehensible input it provides; multimedia technology can help the teaching of the target language and bring a real-life situation into the language classroom. The use of movies in multimedia environment makes it possible to present materials using two modes i.e., verbal and visual, rather than one. However, in EFL classrooms in a country such as Iran, in general, scant attention has been given to the role of movies as regards L2 vocabulary learning.

Using movies, particularly pedagogical movies, in which auditory and visual stimuli are combined, might be one of the effective methods of providing context for vocabulary learning, hence a rich source for incidental vocabulary learning. Pedagogical types of movies are any kinds of movies which are specifically made to benefit the learners; these movies present the real-life language which may be challenging to receive otherwise in a foreign context. Additionally, they are significant in authenticity, the quality, and amount of input presented to the EFL learners (Wang \& Shen, 2007). Although watching movie is a helpful phenomenon, if L2 learners rely just on listening, they would have difficulty in understanding movies. Thus, the subtitling, as a pedagogical tool, has a crucial role in understanding movies. Subtitles, which are used interchangeably with captions, are defined as "the textual versions of the dialog in films and television programs, usually displayed at the bottom of the screen" (Zarei, 2009, p. 86); subtitles in the target language are projected at the bottom of the screen. As Esseberger (2000) asserts, that audio-visual aids can be employed in pedagogical movies in a variety of ways. They can be shown to EFL learners with or without subtitles. It is believed that displaying the subtitles and closed captions ensure learners that none of the words in the conversation will be dropped; the details and additional information accelerate the overall knowledge and the viewer can grasp the material better (Harji, Woods, \& Alavi, 2010).

However, there is growing controversy on the best mode of subtitles in movies as a pedagogical tool in language learning. Pedagogical movies can be watched with controllable or uncontrollable bimodal subtitles, that 
is, target (English) dialogues can be watched with repeated or unrepeated subtitles i.e., captions at the bottom of the TV screen. Perhaps, the EFL learners who are exposed to watching pedagogical movies with controllable bimodal subtitles find it more helpful because they have the opportunity to reiterate several times the vocabularies have not been recognized during viewing the movies. The purpose of this study is to find out which one, English pedagogical movies with repeated or unrepeated English subtitles, can help EFL learners improve their L2vocabulary learning. Therefore, this study aims to explore the comparative effects of two modes of movie subtitling (i.e., controllable or uncontrollable bimodal subtitles) on the EFL learners' vocabulary learning.

\section{Literature Review}

Brown (2000) states that motivation and encouragement are essential factors for EFL learners to learn foreign language intrinsically. Movies along with DVDs are appropriate medium to elicit the students' intrinsic motivation and to contextualize input. Also, according to Zarei, (2009), the use of movies, particularly the subtitled movies, can be one of the most enjoyable, stress-free methods for L2 vocabulary learning. Neuman (1990) conducted a research about the effect of captions/subtitles in foreign language instruction. He designed four different modes to observe 129 minority learners who were in seventh and eighth levels in bilingual programs. He subtitled nine segments of an educational series, which were scientific and lasted 5-8 minutes, in the learners' target language. The results revealed that the learners who watched subtitled series acquired more new words in the target language than in any of the three other conditions. In other words watching movies with subtitles had a positive effect on incidental learning of new vocabulary. Neuman and Koskinen (1992) also believe that there is a rich language environment in Closed Captioned Television (CCTV) which makes the learners acquire vocabulary incidentally through the context while they develop concepts in science. In a study, Neuman and Koskinen (1992) found that using captioned science materials from the TV program "3-2-1 Contact" with Asian and Hispanic seventh and eighth grade English as a second (ESL) students led to higher scores on tests of word knowledge and recall of science information. These results support the theory that multisensory processing of the audio, video, and print components of captioned TV can enhance vocabulary learning.

According to some scholars (e.g., Paivio, 1971; Stewart \& Pertusa, 2004), subtitling can enhance language learners' knowledge of target language in a rich context through the use of new words and lexicons. Ellsworth (1992) conducted research on the controllable subtitled programs. He reported that controllable subtitled programs in a class stimulated the Mexican students to learn their L2 more easily and more confidently. He assigned the students into three presentation modes: 1) captions, 2) non-captions, and 3) only audio. He used vocabulary and grammar consisting of idioms, U.S cultural expectations and slang in his lesson plans. He concluded that those who would feel insecure in L2might be helped by using controllable subtitled videos; they would be able to interact with the controllable subtitled videos and be able to expand their L2 knowledge.

In another study, Koskinen, Knable, Jensema, Markham, and Kane (1995) examined whether subtitled science segments had any effects on the incidental acquisition of L2 vocabulary. The study was completed in a period of nine weeks on $72 \mathrm{~L} 2$ volunteers. The test was mainly about recognition of words, sentence anomaly and the meaning of the words which were recognizable from segments after they had been viewed. The participants were evaluated on their learning of the targeted words. The results showed no significant differences in posttest on the recognition of vocabularies and sentence anomaly.

Danan (1992) states that foreign language learners with an acceptable level of vocabulary knowledge have difficulties in communicating with others. Through controllable captioning, foreign language learners will be encouraged to utilize visual memory and cues. Thus, they feel confident in their own ability to communicate in the target language. Controllable captioning assists L2 learners promote their spelling and writing skill, too. Repeated subtitling, an essential part in learning a foreign language English in class activities, can be an effective aid for improving language skills. In sum, controllable movie subtitles can assist foreign language learners to draw their attention, increase processing and strengthen the previous knowledge. Also, in a study, Koolstra and Beentjes 
(1999) maintained that interlingual subtitles assisted learning pronunciation, syntax, expressions and connotations as well as vocabulary. They found that interlingual subtitling had more advantages than dubbing; it could lead to incidental language learning and was cheaper than dubbing. However, they maintained that there were a number of concerns about subtitling. For instance, it could prevent learners' attention from listening to the dialogues of movies and create problems for children and poor readers.

Concerning the effects of subtitles on vocabulary learning, Bird and Williams (2002) examined the effect of single modality (sound or text) and bimodal (sound and text) presentation on word learning. They concluded that subtitling could improve the learning of novel words. Moreover, Zarei (2009) explored the type of subtitling to find which one was more beneficial for vocabulary recognition and recall. The results showed that bimodal subtitling was the most effective type for vocabulary recognition. More recently, Garnier (2014) examined the potential impact of watching films with subtitles on vocabulary uptake and retention. More specifically, Garnier investigated the vocabulary gains of a post-beginner learner of French from watching the same film once a week for two months in the reversed subtitling condition i.e., with L1 audio and L2 subtitles. The results showed that the participant continually learned new vocabulary after each viewing, while retaining all the words learned in previous weeks.

In sum, most of the studies mentioned so far support the use of subtitled movies in the field of L2 teaching/learning and suggest beneficial effects for vocabulary learning and content comprehension (Etemadi, 2012). However, it seems to be a lack of research on the impact of watching pedagogical movies with controllable and uncontrollable subtitles on vocabulary improvement of Iranian EFL learners. Therefore, this study can be seen as a contribution to fill the gap. In this light, the following question is addressed in this study:

$>\quad$ Is there any significant difference between vocabulary learning of Iranian EFL learners who view pedagogical movies with controllable English subtitles and those who view them with uncontrollable English subtitles?

\section{Methodology}

\subsection{Participants}

Twenty-eight female intermediate-level EFL learners, aged 12-16, participated in the current study. The participants were studying English for almost six terms at two English institutes in Isfahan, Iran. These learners had no contact with native speakers of English and had no exposure to an English speaking community. The EFL learners were placed in two groups. The learners in one of the groups took part in a multimedia classroom in which they viewed an English pedagogical movie with unrepeated i.e., uncontrollable, English subtitling, but the learners in the other group participated in a multimedia classroom in which they viewed an English pedagogical movie with repeated i.e., controllable, English subtitling.

\subsection{Instruments}

To collect data, two instruments were used in this study: a placement and vocabulary test. The Oxford Placement Test (OPT) was employed to select two groups and place the EFL participants in appropriate proficiency levels; it should be mentioned that the reliability and validity of the OPT test had been confirmed. The vocabulary test, which included 30 multiple-choice items, was designed by the present researchers to test the extent to which the participants know the meanings of the target vocabulary in the movie. This vocabulary test lasting for approximately 15 minutes used as the pretest and posttest of the study to evaluate the effect of utilizing repeated and unrepeated subtitles in L2 pedagogical movies in the multimedia EFL classes. The reliability of the vocabulary test was measured using Cronbach alpha. Besides, its validity was verified by factor analysis and the expert judgments. 


\subsection{Procedure}

The data collection was done both quantitatively and qualitatively. First, to select and place EFL learners, OPT was administered. Second, the researcher-made vocabulary test, which had been piloted to make sure that the participants did not know the target vocabularies in the movie so as to have a common base for the comparison of the two groups, was administered to the participants. Meanwhile, the reliability and validity of the test had already been confirmed. It took 15 minutes for the EFL participants in the two groups of the study to answer the test items.

Third, the participants in the two groups watched a movie (named 'Tangled', which was released by Disney Picture in 2010) in two different conditions i.e. with controllable and uncontrollable English subtitles; they were instructed for 10 sessions to learn new words elicited from Tangled. The first group viewed the movie with uncontrollable i.e., unrepeated, English subtitle whereas the second one viewed the movie with controllable i.e., repeated English subtitle. Meanwhile, the content of the English pedagogical movie in the two groups were the same. Both groups of the study had instructional materials and feedback in line with the audio-visual teaching methods. Moreover, the content words in the movie were taught before they watched, while they watching or after they watched the movie. In the group with the English controlled subtitles, caption-on and caption-off activities were carried out so that the EFL learners could practice the content-based vocabularies.

Fourth, after the instructions, the multiple-choice vocabulary test, in which the items were reordered, was administered as the posttest to compare the differences in vocabulary improvement in the two groups of the study. Finally, analysis of covariance (ANOVA), an extension to repeated-measured ANOVA, was run through SPSS to show the main effects of the group difference (independent variable) in the current study.

\section{Results}

The descriptive data of the EFL participants' vocabulary scores in the controllable English subtitle (CES) and uncontrollable English subtitle (UES) groups are demonstrated in Table 1.

\section{Table 1}

Descriptive Statistics of the two Subtitle Groups (CES and UES)

\begin{tabular}{llcccccc}
\hline & & $\mathrm{N}$ & Mean & Std. Deviation & Std. Error & Minimum & Maximum \\
\hline Pretest & CES & 14 & 9.14 & 4.348 & 1.162 & 3 & 15 \\
& UES & 8 & 8.25 & 2.435 & .861 & 6 & 12 \\
& Total & 22 & 8.82 & 3.724 & .794 & 3 & 15 \\
\hline Posttest & CES & 14 & 23.43 & 3.131 & .837 & 17 & 27 \\
& UES & 8 & 19.00 & 3.625 & 1.282 & 15 & 24 \\
& Total & 22 & 21.82 & 3.899 & .831 & 15 & 27 \\
\hline
\end{tabular}

As Table 1 shows, the vocabulary mean scores of the pretests were not equal for both UES and UES groups ( $M=9.14$ and $M=8.25$, respectively). However, concerning the vocabulary mean scores of the posttests, the participants in the CES group gained higher posttest mean scores than did the participants in the UES group (see Figure 1). 


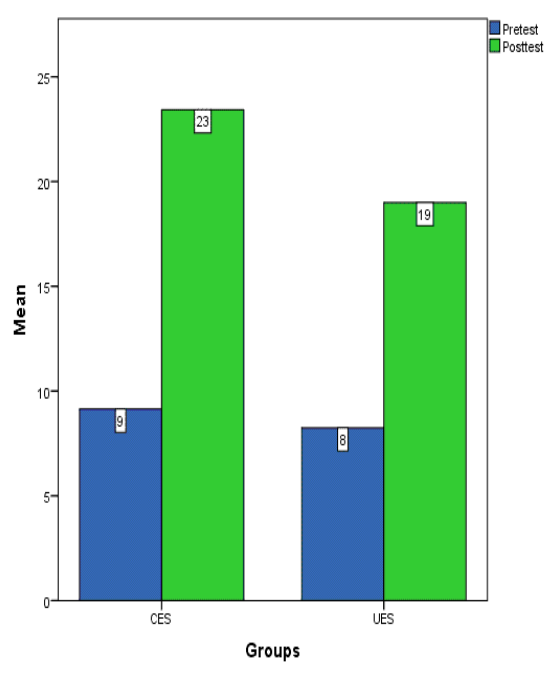

Figure 1. Bar graph of pretest and posttest scores in the CES and UES groups

The first research question was intended to explore if there was any significant difference in vocabulary improvement between those who viewed the pedagogical movie with controllable English subtitles and those who watched it with uncontrollable English subtitles. To address this question a one-way ANCOVA was conducted. Prior to running the ANCOVA, preliminary assumptions of normality, linearity, homogeneity of variances, homogeneity of regression slopes, and reliable measurement of the covariate were checked. The results showed no serious violations of the assumptions. ANCOVA was carried out to examine if there was a significant difference between the vocabulary posttest scores in the two groups while pretest scores were held constant. Table 2 reports the adjusted mean scores of the vocabulary posttest.

Table 2

Descriptive statistics of Adjusted Mean Scores of the Posttests in the Two Groups

\begin{tabular}{lccccc}
\hline & \multirow{2}{*}{ Group } & \multirow{2}{*}{$\mathrm{M}$} & \multirow{2}{*}{ Std. Error } & \multicolumn{2}{c}{ Confidence Interval (95\%) } \\
\cline { 4 - 5 } & & & Lower Bound & Upper Bound \\
\hline CES & 23.296 & .805 & 21.610 & 24.982 \\
UES & 19.232 & 1.067 & 16.998 & 21.466 \\
\hline
\end{tabular}

As Table 2 reports, the adjusted vocabulary mean scores for the CES group in the posttest was higher than that of the UES group $(M=19.23)$. To see if the difference between the adjusted vocabulary posttest scores was significant and answer the first research question, a one-way ANCOVA was run with the posttest scores as dependent and the groups of the study as independent variables; the pretest scores were also considered as the covariate in the ANCOVA. The results are reported in Tables

Table 3

One-way ANCOVA for Group Effect on the Vocabulary Scores

\begin{tabular}{lllcccc}
\hline & \multicolumn{2}{l}{ Type III Sum of } & & & \multicolumn{2}{c}{ Partial Eta } \\
Source & Squares & $d f$ & Mean Square & $F$ & Sig. & Squared \\
\hline Corrected Model & 147.622 & 2 & 73.811 & 8.170 & .003 & .462 \\
Intercept & 999.084 & 1 & 999.084 & 110.588 & .000 & .853 \\
Pretest & 47.778 & 1 & 47.778 & 5.289 & .033 & .218 \\
Group & 82.927 & 1 & 82.927 & 9.179 & .007 & .326 \\
Error & 171.651 & 19 & 9.034 & & & \\
Total & 10792.000 & 22 & & & & \\
\hline Corrected Total & 319.273 & 21 & & & & \\
\hline
\end{tabular}


As Table 4 displays, the results of the ANCOVA revealed that the difference was statistically significant between the CES and UES groups regarding the vocabulary posttest scores, $F=9.179, p=.007$. The partial eta squared, indicating the effect size of the treatment, was found to be large (.326), meaning that about $32 \%$ of variance in the posttest scores were due to the treatment effect. In sum, the data analysis revealed that EFL learners' vocabulary gains were significantly higher when the controllable English subtitles were used in the classroom.

\section{Discussion}

The main purpose of the current research was to examine whether watching English pedagogical movies with controllable (repeated) or uncontrollable (unrepeated) subtitles had any effect on the Iranian EFL participants' vocabulary knowledge. A plethora of studies exist about the effects of English movie subtitling on L2 earners' vocabulary improvement. Most of these studies in line with the present study indicate that subtitling would have positive effects on vocabulary learning. For instance, Bean and Wilson (1989) reported that their participants who were non-native speaking adults had highly positive attitudes toward subtitling and they had a great progress in L2 vocabulary; those L2 learners who watched L2 subtitled materials greatly improved in learning vocabulary, word recognition, listening comprehension and reading comprehension. Also, in the context of Iran, Alipour, Gorjian, and Gholampour Kouravand (2012) investigated the effects of pedagogical and authentic movies with English and Persian subtitles on 90 EFL learners' vocabulary learning. In their study, the participants were divided into two homogenous groups as the pedagogical and authentic groups and watched several English movies with English and Persian subtitles. The results of their study revealed that those participants who watched the movies with English subtitles outperformed better.

Furthermore, the findings of the present research are in line with the studies conducted by Neuman (1990), Danan (1992), Jones (2004), and Mitterer and McQueen (2009), who reported that English subtitled groups showed the highest level of proficiency regarding the vocabulary learning. The above findings of the present study are in line with the studies conducted by Neuman and Koskinen (1992), Vanderplank (1988), and Koskinen, Wilson, and Jensema (1985), demonstrating that controllable subtitling had a significant and positive impact on learners' L2 skills. Nonetheless, some claims made by several researchers can challenge the results of the current research. For instance, Vandergrift (2004) believes that for language learners to be able to improve their listening comprehension, it is important to learn to be dependent on what they hear and on the relevant clues which are contextualized. Language learners should understand that in real-time listening situations the words and written texts are not usually available. Therefore, teachers should use movies without subtitles to facilitate the visual context for understanding what the speakers say. Besides, in real world, they are not exposed to subtitles when they are trying to interact or communicate with non-native speakers. Stewart and Pertusa (2004) also claim subtitling in movies is a major obstacle in the English listening comprehension. Moreover, Moreno and Mayer (2007) argue that utilizing subtitled movies is not useful in L2 classroom because the subtitling in movies may overload the visual channel by presenting visuals, texts, and verbal data at the same time in learners' working memory; hence, this issue can reduce meaningful learning.

Nonetheless, many L2 learners encounter problems when communicating in real-life contexts even though they know the meaning of the vocabularies. L2 learners are encouraged to make use of visual memory and cues by controllable subtitling; they retain confidence to communicate in the target language. Besides, controllable subtitling assists L2 learners develop their spelling and writing ability. Using repeated subtitling in class activities can be effective for learning language skills; controllable subtitles in movies can aid L2 learners in analyzing the target language, improving processing and strengthening their background knowledge. EFL learners who viewed an English pedagogical movie with controllable English subtitles benefit because they find the opportunity to repeat many times the vocabularies that they have not noticed during viewing the movie. This issue can stress the role of repeated subtitling in improving Iranian EFL learners' vocabulary learning. 


\section{Conclusion and Implications}

This study explored the comparative effects of two subtitling formats i.e., controllable and uncontrollable subtitles in an English movie ('Tangled') on the EFL learners' vocabulary improvement. The findings showed that the EFL participants watching the movie containing controllable i.e., repeated, English subtitles obtained a higher mean score on the content-specific vocabulary test, compared with those who viewed the movie with uncontrollable English subtitles. The results of the present research also provide support for the effectiveness of using English subtitles to improve EFL learners' vocabulary learning.

The findings indicate that learning target vocabulary through viewing pedagogical movies containing target language subtitles, particularly controllable subtitles, can assist EFL learners with negative attitudes towards English greatly. Not only viewing subtitles can aid EFL learners to acquire the new English vocabulary easier, but also it can make them have interaction with each other in an effective learning environment. The presence of controllable subtitles can guarantee that not a single word from the dialogues is missed by the EFL learners. Additional input allows them to understand their instructional materials better and improve their overall language learning.

Furthermore, the results obtained from the current study reveal that, unlike boring traditional teaching methods, the methods which use audiovisual aids such as movies, in general, and movie subtitles, in particular, can be influential in language teaching and improve L2 learners' vocabulary learning. Besides, the role of subtitles in improving L2 vocabulary learning can be crucial and should not be neglected. L2 vocabulary learning can be more effective when subtitled movies are used as a means for the explicit teaching of target vocabulary. As Mélodie (2014) states, explicit instruction remains the most efficient route to learning and retaining new words. By implications, syllabus designers and materials developers can adapt vocabulary exercises in L2 instructional materials by considering the use of multimedia and subtitled pedagogical movies in L2 classes. L2 learners can benefit from engaging in movie-watching as an aid for learning new vocabulary in a stress-free environment; they should be explicitly encouraged to pay attention to the L2 subtitles and make necessary pauses for taking notes or rewinding.

\section{References}

Alipour, M., Gorjian, B., \& Gholampour Kouravand, L. (2012). The effects of pedagogical and authentic films on EFL learners' vocabulary learning: The role of subtitles. Advance in Asian Social Science, 3(4), 2167-6429.

Amiryousefi, M. (2015). Iranian EFL teachers and learners' beliefs about vocabulary learning and teaching. International Journal of Research Studies in Language Learning, 4(4), 29-40. http://dx.doi.org/10.5861/ijrsll.2015.1016

Bean, R., \& Wilson, R. (1989). Using closed-subtitled television to teach reading to adults. Reading Research Instruction, 28(4), 27-37. http://dx.doi.org/10.1080/19388078909557984

Bird, S. A., \& Williams, J. N. (2002). The effect of bimodal input on implicit and explicit memory: An investigation into the benefits of within-language subtitling. Applied Psycholinguistics, 23(4), 509-533. http://dx.doi.org/10.1017/S0142716402004022

Bisson, M. J. (2013). Incidental acquisition of foreign language vocabulary through multi-modal situations. Unpublished doctoral dissertation, University of Nottingham, UK.

Brett, P. (1995). Multimedia for listening comprehension: The design of a multimedia-based resource for developing listening skills. System, 23, 77-85. http://dx.doi.org/10.1016/0346-251X(94)00054-A

Brown, H. D. (2000). Principles of language learning and teaching. New York: Longman.

Danan, M. (1992). Reversed subtitling and dual coding theory: New direction for foreign language instruction. Language Learning, 42(4), 497-527. http://dx.doi.org/10.1111/j.1467-1770.1992.tb01042.x

Egbert, J. L., \& Jessup, L. M. (1996). Analytic and systemic analyses of computer-supported language learning environments. TESL-EJ, 2, 1-24. 
Effects of pedagogical movie English subtitles on EFL learners' vocabulary improvement

Ellsworth, T. (1992). Integrating subtitled video into your teaching. English Teaching Forum, 30(3), $24-27$.

Esseberger, J. (2000). Notes on using video in the language classroom. If you can read this, thank TV. TESOL Journal, 6(2), 15-18.

Etemadi, A. (2012). Effects of bimodal subtitling of English movies on content comprehension and vocabulary recognition. International journal of English linguistics, 2(1), 239-248. http://dx.doi.org/10.5539/ijel.v2n1p239

Garnier, M. (2014). Intentional vocabulary learning from watching DVDs with subtitles: A case study of an 'average' learner of French. International Journal of Research Studies in Language Learning, 3(1), 21-32. http://dx.doi.org/10.5861/ijrsll.2013.521

Harji, B. M., Woods, C. P., \& Alavi, Z. K. (2010). The effect of viewing subtitled videos on vocabulary learning. Journal of College Teaching \& Learning, 7(9), 37-42.

Hunt, A., \& Beglar, D. (1998). Current research and practice in teaching vocabulary. The Language Teacher Online, 22(1), 1-9.

Jones, L. (2004). Testing L2 vocabulary recognition and recall using pictorial and written test items. Language Learning \& Technology, 8(3), 122-143.

Khalid, A. S. (2001). The effect of multimedia annotation modes on L2 vocabulary acquisition: A comparative study. Language, Learning \& Technology, 5(1), 110-121.

Koolstra, C. M., \& Beentjes, J. W. J. (1999). Children's vocabulary acquisition in a foreign language through watching subtitled television programs at home. Educational Technology Research Development, 47(1), 51-60. http://dx.doi.org/10.1007/BF02299476

Koskinen, P., Knable, J., Jensema, C., Markham, P., \& Kane, K. (1995) Subtitled television and the vocabulary acquisition of adult second language correctional facility residents. Journal of Educational Technology Systems, 24(4), 359-373. http://dx.doi.org/10.2190/JKC2-LE5D-36BC-809F

Koskinen, P., Wilson, R., Jensema, C. (1985). Closed-captioned television: A new tool for reading instruction. Reading World, 24, 1-7. http://dx.doi.org/10.1080/19388078509557842

Laufer, B., \& Ravenhorst-Kalovski, G. C. (2010). Lexical threshold revisited: Lexical text coverage, learners' vocabulary size and reading comprehension. Reading in a Foreign Language, 22(1), 15-30.

Mitterer, H., \& Mc Queen, J. M. (2009). Foreign subtitles help but native-language subtitles harm foreign speech perception. PloS One, 4(11), 146-150. http://dx.doi.org/10.1371/journal.pone.0007785

Moreno, R., \& Mayer, R. E. (2007). Interactive multimodal learning environments. Educational Psychology Review, 19(3), 309-326. http://dx.doi.org/10.1007/s10648-007-9047-2

Nagy, W. (1997). On the role of context in first-and second-language vocabulary learning. In N. Schmitt \& M. McCarthy (Eds.), Vocabulary: description, acquisition and pedagogy. Cambridge: Cambridge University Press.

Neuman, S. (1990). Using subtitled television to improve the reading proficiency of language minority students. Falls Church, VA: National Captioning Institute.

Neuman, S. B., \& Koskinen, P. (1992). Captioned television as comprehensible input: Effects of incidental word learning from context for language minority students. Reading Research Quarterly, 27(1), 94-106. http://dx.doi.org/10.2307/747835

Paivio, A. (1971). Imagery and cognitive process. New York: Holt, Rinehart \& Winston.

Stewart, M., \& Pertusa, I. (2004). Gains to language learners from viewing target language closed-captioned films. Foreign Language Annals, 37(3), 438-447. http://dx.doi.org/10.1111/j.1944-9720.2004.tb02701.x

Vandergrift, L. (2004). Listening to learn or learning to listen. Annual Review of Applied Linguistics, 24, 3-25. http://dx.doi.org/10.1017/s0267190504000017

Vanderplank, R. (1988). The value of teletext sub-titles in language learning. ELT Journal, 42(4), $272-281$. http://dx.doi.org/10.1093/elt/42.4.272

Wang, Y. C. (2012). Learning L2 vocabulary with American TV drama from the learner's perspective. English Language Teaching, 5(8), 217-225. http://dx.doi.org/10.5539/elt.v5n8p217

Wang, Y., \& Shen, C. (2007). Tentative model of integrating authentic captioned video to facilitate ESL learning. Sino-Us English Teaching, 4(9), 1-13. 
Rostam Shirazi, R., Hesabi, A., \& Simin, S.

Yang-dong, W., \& Cai-fen, S. (2007). Tentative model of integrating authentic captioned video to facilitate ESL learning. PLA University of Foreign Languages, 4(9). Retrieved from http://www.linguist.org.cn/doc/su200709/su20070901.pdf

Zarei, A. A. (2009). The effect of bimodal, standard, and reversed subtitling on L2 vocabulary recognition and recall. Pazhuhesh-e Zabanha-ye Khareji, 49, 65-84.

Zarei, A. A., \& Gujjar, A. A. (2012). The contribution of electronic and paper dictionaries to Iranian EFL learner's vocabulary learning. International Journal of Social Sciences and Education, 2(4), 628-634. 